EMMENSITE NO, 5 .

\begin{tabular}{|c|c|c|c|}
\hline $\begin{array}{c}\text { Initial temp. } \\
\sim 0^{\circ} \mathrm{C} .\end{array}$ & $\begin{array}{c}\text { Firing point. } \\
205^{\circ} \mathrm{C} .\end{array}$ & $\begin{array}{c}\text { Intitial temp. } \\
150^{\circ} \mathrm{C} .\end{array}$ & $\begin{array}{l}\text { Firing point. } \\
\qquad 210^{\circ} \mathrm{C} .\end{array}$ \\
\hline $100^{\circ}$ & $210^{\circ}$ & $180^{\circ}$ & $21 \%$ \\
\hline $115^{\circ}$ & 2150 & $190^{\circ}$ & $209^{\circ}$ \\
\hline $130^{\circ}$ & $211^{\circ}$ & $200^{\circ}$ & $21 \%$ \\
\hline
\end{tabular}

This was received and stored like No. $\therefore$.

\title{
THE MANUFACTURE OF COMMERCIAL HYDROGEN DIOXIDE AND I'TS APPLICATIONS.
}

\section{By A. Botrgougnon.}

Since Bloxam, in the last edition of his "Chemistry, Inorganic and Organic," (London, 1888, p. 55), makes the following statement: "This compound $\left(\mathrm{H}_{2} \mathrm{O}_{2}\right)$. . . . . has no very important useful application in the arts." I have deemed it wise to state what has been and is now done in this country with this article. Bloxam's remar'k is perfectly true as far as pure hydrogen dioxide is concerned, but is, nevertheless, misleading. Solutions of hydrogen dioxide are now manufactured in a commercial way and chiefly applied to bleaching purposes.

My first experiments in manufacturing hydrogen dioxide were conducted in 1873 under very unfavorable circumstances; the barium dioxide which could be obtained in this city was of a very inferior quality and quoted as high as $\$ 1.50$ per ounce. I followed the method of preparation described by Thenard in 1818, and all I could produce was employed by hair dealers in their trade.

In 18:8 I manufactured hydrogen dioxide on a commercial scale, and the following is a description of the method I adopted for the preparation of this bleaching compound:

The first step, and a very important one, is the liydration of the barium dioxide.

Into a suitable ressel, an ordinary cylindrical stone pot, about half full of water, the powdered dioxide is slowly poured, the mix- 
ture being well stirred with a wooden spatula during this operation, and continued after its completion for about twenty minutes. Then the mixture is left alone and stirred every half hour, or oftener, for about ten minutes, until the hydration is completed. This operation requires from three to four hours; the barjum dioxide forms then a thick, perfectly white and smooth, pasty mass resembling white clay mixed with water.

While the hydration is progressing a mixture of water and hydrofluoric acid is made in a vessel lined with sheet lead and surrounded with ice or simply with water in which lumps of ice are placed from time to time so as not to allow the acid mixture to rise above $10^{\circ} \mathrm{C}$. during the operation.

All things being properly disposed, the nydrated barium dioxide is added in portions of three to four pounds at a time to the acid mixture, stirring all the time to mix the contents of the vessel thoroughly. All the barium is transferred to the acidulated water in about two hours and the agitation continued for four hours. If the operation has been well conducted, all the barium dioxide is transformed into fluoride, which falls to the bottom of the ressel. When this precipitate is well settled, the supernatant liquid is decanted into a vessel similar to the one used for its production, and also surrounded by ice water. The clear liquid contains an excess of acid and impurities derived from the materials employcd, its color is yellowish and it must be purified to insure its keeping properties.

The impurities which are to be removed are chiefly ferric oxide, alumina and manganese oxide. To the cold solution of impure hydrogen dioxide small quantities of hydrated barium dioxide are added at a time and well stirred. When the last traces of acid are saturated, the appearance of the liquid suddenly changes, from a bright yellow it turns to a greyish color, the impurities are separated and collect at the surface of the liquid.

Without losing time the liquid is filtered through a cheese cloth stretched on a frame, and received in a ressel which contains a small quantity of sulphuric acid diluted with eight to ten times its volume of water (acid, one ounce; water, 8-10 ounces). This filtration must be quickly done. As long as the solution is alkaline 
there is great danger of decomposition and loss of oxygen. If the liquid is thrown upon the filter, the latter will be quickly clogged, the filtration stopped, and the hydrogen dioxide will rapidly decompose, emitting large bubbles of oxygen with a hissing noise, but as the precipitated impurities collect first on the top of the liquid, the solution is syphoned from below these impurities, the liquid filters quickly and satisfactorily. The filtered liquid is tested for barium, and sulphuric acid is added to it until all is removed. The liquid is left over night, the precipitate of barium sulphate settles and the perfectly clear aud colorless liquia is ready for the market.

All the precipitates are separated, by pressure, from the liquid they may contain, and the liquid so obtained is added to the water employed in the next operation.

I employed the following proportions:

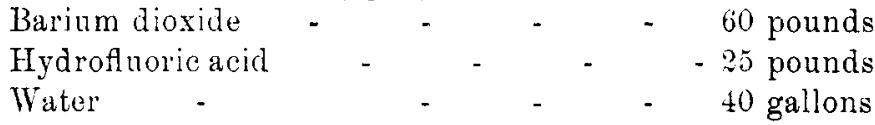

and obtained nearly forty gallons of hydrogen dioxide. The strength of the acid was about 33 per cent.

Commercial hydrogen dioxide can be produced at the following figures:

60 lbs. Barium dioxide @ 25c. - - $\quad-\quad \$ 1500$

25 lbs. Hydrofluoric acid (218c. 18 - $\quad-\quad 450$

Ice

$-\quad 50$

$\$ 2000$

or fifty cents per gallon for the materials used in the manufacture. The price of 18 cents per pound for hydrofluoric acid is high.

Other methods could be employed for manufacturing hydrogen dioxide. Before adopting hydrofluoric acid I used oxalic acid, but this is not to be recommended, not only on account of the price, but because some acid may be left in the solution.

The method recommended by Thomsen consists in dissolving the barium dioxide in dilute nitric acid and when nearly all the acid is saturated, an excess of baryta water is added, hydrated barium dioxide is thrown down, is separated, washed and agitated with water containing one-third of its weight of sulphuric acid. In 
this process, part of the barium can be recovered; during the treatment of the dioxide with hydrated nitric acid, a large amount of barium nitrate is separated from the liquid and this salt may be easily reconverted into barium dioxide. A stream of carbon dioxide conducted into water in which barium dioxide is added produces nydrogen dioxide, but the solution thus obtained, although rery pure, is too weak for industrial applications.

'The commercial solutions of hydrogen dioxide are said to contain about fifteen times their volume or useful or active oxygen. The test is made by adding to the solution sulphuric acid and potassium permanganate and measuring the volume of oxygen evolved. This method is incorrect (see my paper, this journal, June, 1889). A small amount of oxalic acid would greatly increase the volume of gas liberated.

'The first application of hydrogen dioxide on a large scale in the United States was due to the experiments made in $18^{7} 8$ by Prof. R. Ogden Doremus in the bleaching of ostrich feathers. The process was kept secret for about a year and a half, after which it came into general use, and the manufacture of hydrogen dioxide then developed rapidly to its present extensive proportions.

Ostrich feathers are imported in bunches and are very dirty. They are strung and well washed with soap and warm water; they are afterwards rinsed until the wash water is clear and then partially dried. For the soap generally used I have substituted sodium silicate with very good results and a great saving of labor. When the feathers are clean they are immersed in the bleaching solution rendered alkaline with a slight excess of ammonia and abandoned to the action of nascent oxygen for about twelve hours, then well washed with soap or sodium silicate and warm water and rinsed, the last water containing starch, and they are beaten until dried. If one bath is not sufficient the operation is repeated. The feathers become white. Hair in commercial transactions is known as "human" and "Chinese." Chinese hair is bleached more extensively than human, because it is cheaper and its strength allows it to be submitted to such treatment without being too much injured. For bleaching human hair the same process is employed as for fea- 
thers. For Chinese hair the first step is to render it thinner; this is done by immersions in a solution of alkaline hypochlorites, or a solution of potassium chlorate and hydrochloric acid. When the hair is "refined" it is treated like human hair; but to obtain a perfect bleaching several baths are required, sometimes as many as twelve to fifteen, and yet the white is not pure: it retains a yellowish hue which does not entirely disappear by bluing.

The very white and silky looking hair which is seen in the stores is not human ; it is obtained from the yak (Poeplagus grunniens, Linn), an animal native to the mountains of Thibet. Hydrogen dioxide is also employed to change the color of dark hair to a lighter shade. Two or three applications make the hair turn red; if continued longer a light blonde is obtained.

It might happen that some persons would have recourse to these means to conceal their identity, but it will be very easy to discover if the hair has been discolored. After about a week the newly grown hair will be darker near the roots than in their other parts.

Several other materials are bleached with hydrogen dioxide, among them wood, ivory, whalebone, silk, tetc.

'I'usah or wild silk is very easily bleached. It is first boiled with soap water, rinsed and transferred to the bleaching bath. I have found that a solution of hydrogen dioxide, prepare? in a very rudimentary way, is all that is necessary to bleach this kind of silk.

The hydrated barium dioxide is simply dissolved in dilnte hydrochloric acid, and, without removing the impurities or the barium, the solution is ready to be employed after being made alkaline with ammonia. When the silk is removed from the bath it is well washed, and to the last rinsing some hydrochloric acid is added.

When hydrogen dioxide was discovered in 1818 by 'Thenard, it was thought that this new compound could be advantageously employed as a medicine. Experiments carefully conducted in Englaud failed to sustain this claim, but, nevertheless, if hydrogen dioxide is worthless as a medicine, it is a powerful antiseptic. In September, 1888, I had the opportunity of witnessing this im- 
portant property. A lady suffering from cancer had had one breast amputated; at the suggestion of Prof. R. O. Doremus, hydrogen dioxide was selected as an antiseptic and the results were very favorable, the wound healed quickly without suppuration. In such cases, pure solutions must be employed; the commercial product contains free acids and when vaporized in a room produces irritation of the throat and coughing.

In conclusion, I will state that I do not believe that the manufacture of commercial hydrogen dioxide is susceptible of much development. Its chief application, the bleaching of ostrich and fancy feathers, is controlled by fashion; its use for changing the color of live hair is rapidly decreasing, henna (Lawsania Inermis) which is less objectionable being a substitute. The high price of production forbids its application for the bleaching of comparatively low priced products, and unless new applications are found and the price of manufacturing greatly reduced, the demand for hydrogen dioxide cannot be increased.

Nevertheless, the preparation of hydrogen dioxide, on a comparatively large scale, is carried out in New York by the introduction of several improvements whereby as much as two hundred gallons are obtained in one operation; the stirring of the working vats is done by steam power, and the qualities of the product, which are always uniform, are highly commended and appreciated by the trade.

\section{GENERAL CHEMISTRY.}

On the Presence of Nitrous Acid in the Atmosphere. L. T. LoswaY.

In his experiments the author finds some form of combined nitrogen constantly present upon the surface of grass, leaves and branches. In clear and dry weather ammonium nitrite is converted into nitrate, either by the oxygen from the leaves or by atmospheric oxygen under the influence of sunlight. He has also found nitrous acid in the water of soils of different kinds after washing 